Supporting Information

\title{
Photothermal Fabrics for Efficient Oil-Spill \\ Remediation via Solar-driven Evaporation \\ Combined with Adsorption
}

Bon-Jun Ku, Byoung-Min Lee, Dong Hyun Kim, Anush Mnoyan, Sung-Kwon Hong, Kang Seok Go, Eun Hee Kwon, Shin-Hyun Kim, * Jae-Hak Choi, * and Kyubock Lee*

* Corresponding authors: kyubock.lee@cnu.ac.kr (K. Lee), jaehakchoi@cnu.ac.kr (J.-H. Choi), kim.sh@kaist.ac.kr (S.-H. Kim) 


\section{Estimation of the photothermal evaporation efficiency}

The photothermal evaporation efficiency was calculated by following the equation below [1]. Here, we assumed that the vapor temperature is same with the boiling point of the organic solvent and calculated the efficiency as follows:

$$
\eta=\frac{\Delta m \cdot H}{I} \times 100(\%),
$$

where $\Delta m$ is the evaporation rate of the organic solvent $\left(\mathrm{kg} \mathrm{m}^{-2} \mathrm{~h}^{-1}\right), H$ is the total enthalpy of liquid-vapor phase change (the sensible heat, $Q$, and Enthalpy of vaporization, $h, \mathrm{~kJ} \mathrm{~kg}^{-1}$ ), and $I$ is the illumination intensity $\left(\mathrm{kW} \mathrm{m}^{-2}\right)$. The efficiencies for three model oils are summarized in Table S1 and Table S2. The sensible heat is the energy required to change the temperature of a substance with no phase change.

Table S1. The calculated evaporation efficiency and other parameters (with C270).

\begin{tabular}{|c|c|c|c|c|c|c|c|c|c|c|}
\hline & $\begin{array}{c}\text { Molar } \\
\text { mass } \\
(\mathrm{g} / \mathrm{mol})\end{array}$ & $\begin{array}{c}h \\
(\mathrm{~kJ} \mathrm{~kg}-1)\end{array}$ & $\begin{array}{c}\mathrm{C} \\
\left(\mathrm{kJ} \mathrm{kg}^{-1} \mathrm{~K}^{-1}\right)\end{array}$ & $\begin{array}{c}\text { Boiling } \\
\text { point (K) }\end{array}$ & $\begin{array}{c}\mathrm{Q} \\
\left(\mathrm{kJ} \mathrm{kg}^{-1}\right)\end{array}$ & $\begin{array}{c}H=h+Q \\
\left(\mathrm{~kJ} \mathrm{~kg}^{-1}\right)\end{array}$ & $\begin{array}{c}\Delta \mathrm{m} \\
\left(\mathrm{kg} \mathrm{m}^{-2} \mathrm{~h}^{-1}\right)\end{array}$ & $\begin{array}{c}\mathrm{I} \\
\left(\mathrm{kW} \mathrm{m}^{-2}\right)\end{array}$ & $\begin{array}{c}\mathrm{I} \\
\left(\mathrm{kJ} \mathrm{m} \mathrm{m}^{-2} \mathrm{~h}^{-1}\right.\end{array}$ & $\begin{array}{c}\eta \\
(\%)\end{array}$ \\
\hline Octane & 114.23 & 372.00 & 2.24 & 398.7 & 225.57 & 597.57 & 0.54 & 1 & 3600 & 8.96 \\
\hline Decane & 142.28 & 361.96 & 2.22 & 447.2 & 331.22 & 646.68 & 0.22 & 1 & 3600 & 3.95 \\
\hline Dodecane & 170.33 & 360.48 & 2.21 & 489.2 & 422.55 & 783.03 & 0.09 & 1 & 3600 & 1.96 \\
\hline
\end{tabular}

Table S2. The calculated evaporation efficiency and other parameters (without C270).

\begin{tabular}{|c|c|c|c|c|c|c|c|c|c|c|}
\hline & $\begin{array}{c}\text { Molar } \\
\text { mass } \\
(\mathrm{g} / \mathrm{mol})\end{array}$ & $\begin{array}{c}h \\
\left(\mathrm{~kJ} \mathrm{~kg}^{-1}\right)\end{array}$ & $\begin{array}{c}\mathrm{C} \\
\left(\mathrm{kJ} \mathrm{kg} \mathrm{K}^{-1}\right)\end{array}$ & $\begin{array}{c}\text { Boiling } \\
\text { point (K) }\end{array}$ & $\begin{array}{c}\mathrm{Q} \\
\left(\mathrm{kJ} \mathrm{kg}^{-1}\right)\end{array}$ & $\begin{array}{c}H=h+Q \\
\left(\mathrm{~kJ} \mathrm{~kg}^{-1}\right)\end{array}$ & $\begin{array}{c}\Delta \mathrm{m} \\
\left(\mathrm{kg} \mathrm{m}^{-2} \mathrm{~h}^{-1}\right)\end{array}$ & $\begin{array}{c}\mathrm{I} \\
\left(\mathrm{kW} \mathrm{m}^{-2}\right)\end{array}$ & $\begin{array}{c}\mathrm{I} \\
\left(\mathrm{kJ} \mathrm{m} \mathrm{m}^{-1}\right)\end{array}$ & $\begin{array}{c}\eta \\
(\%)\end{array}$ \\
\hline Octane & 114.23 & 372 & 2.24 & 398.7 & 225.57 & 597.57 & 0.27 & 1 & 3600 & 4.48 \\
\hline Decane & 142.28 & 361.96 & 2.22 & 447.2 & 331.22 & 646.68 & 0.05 & 1 & 3600 & 0.9 \\
\hline Dodecane & 170.33 & 360.48 & 2.21 & 489.2 & 422.55 & 783.03 & 0.04 & 1 & 3600 & 0.87 \\
\hline
\end{tabular}




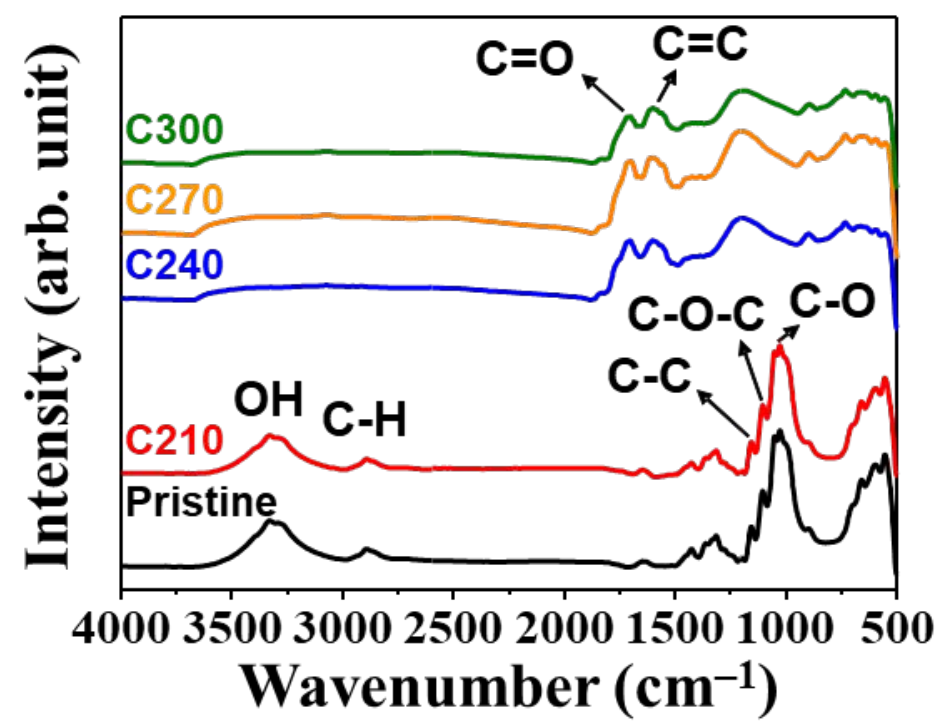

Figure S1. FTIR spectra of the pristine non-woven cotton fabric, C210, C240, C270, and C300.
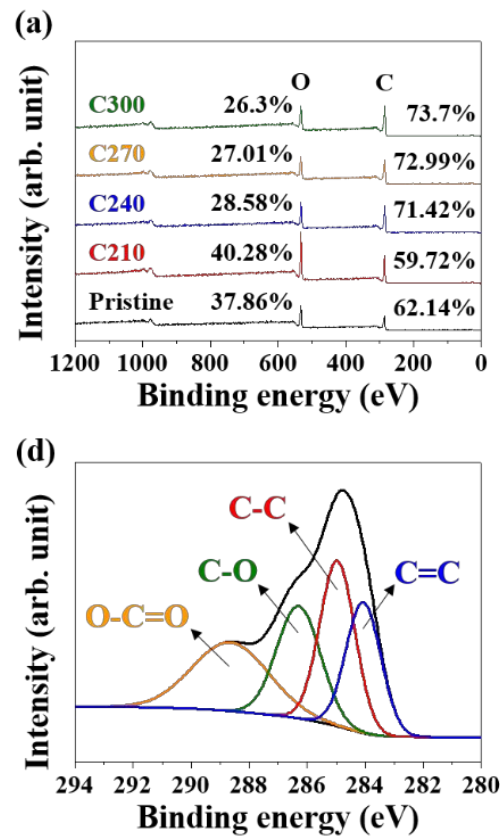
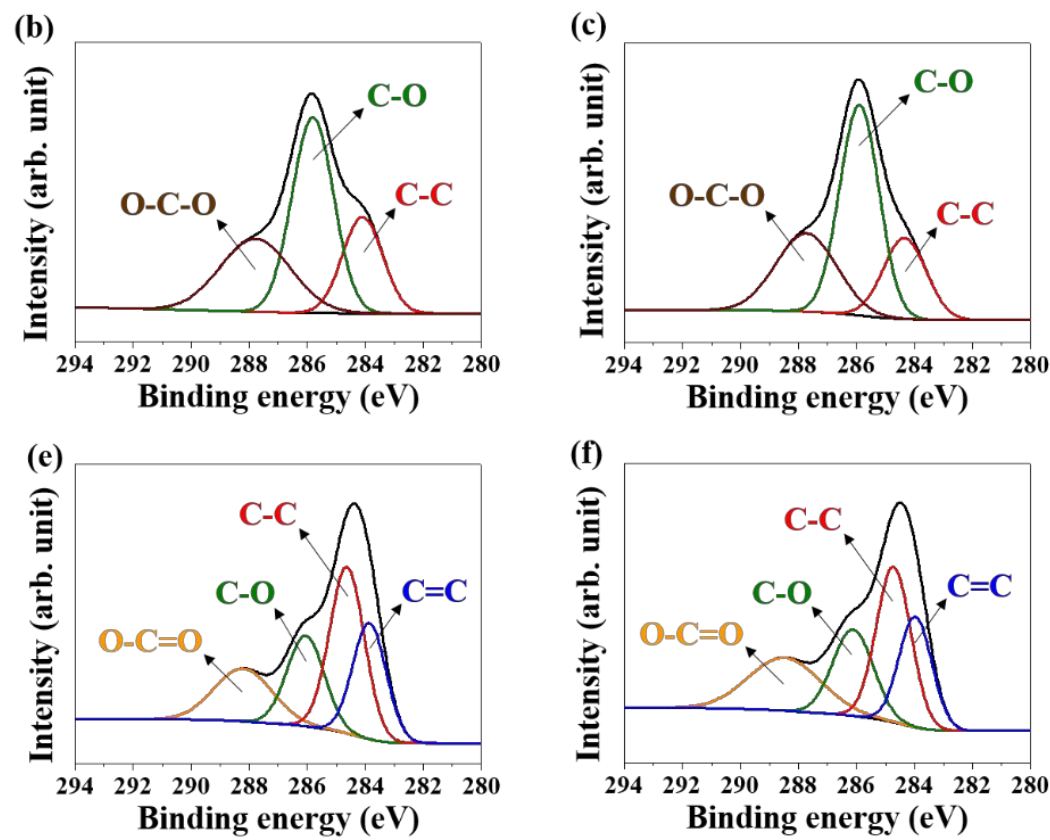

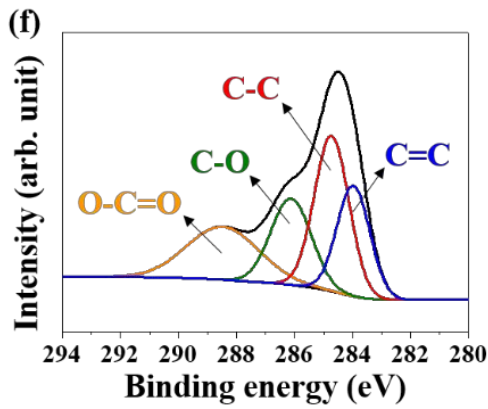

Figure S2. (a) XPS survey spectra of the pristine fabric, C210, C240, C270, and C300. (b-e) XPS $\mathrm{C} 1$ s narrow spectra and deconvoluted peaks for $\mathrm{O}-\mathrm{C}-\mathrm{O}, \mathrm{C}-\mathrm{O}, \mathrm{C}-\mathrm{C}, \mathrm{O}-\mathrm{C}=\mathrm{O}$, and $\mathrm{C}=\mathrm{C}$ bonds of (b) the pristine fabric, (c) C210, (d) C240, (e) C270, and (f) C300. 

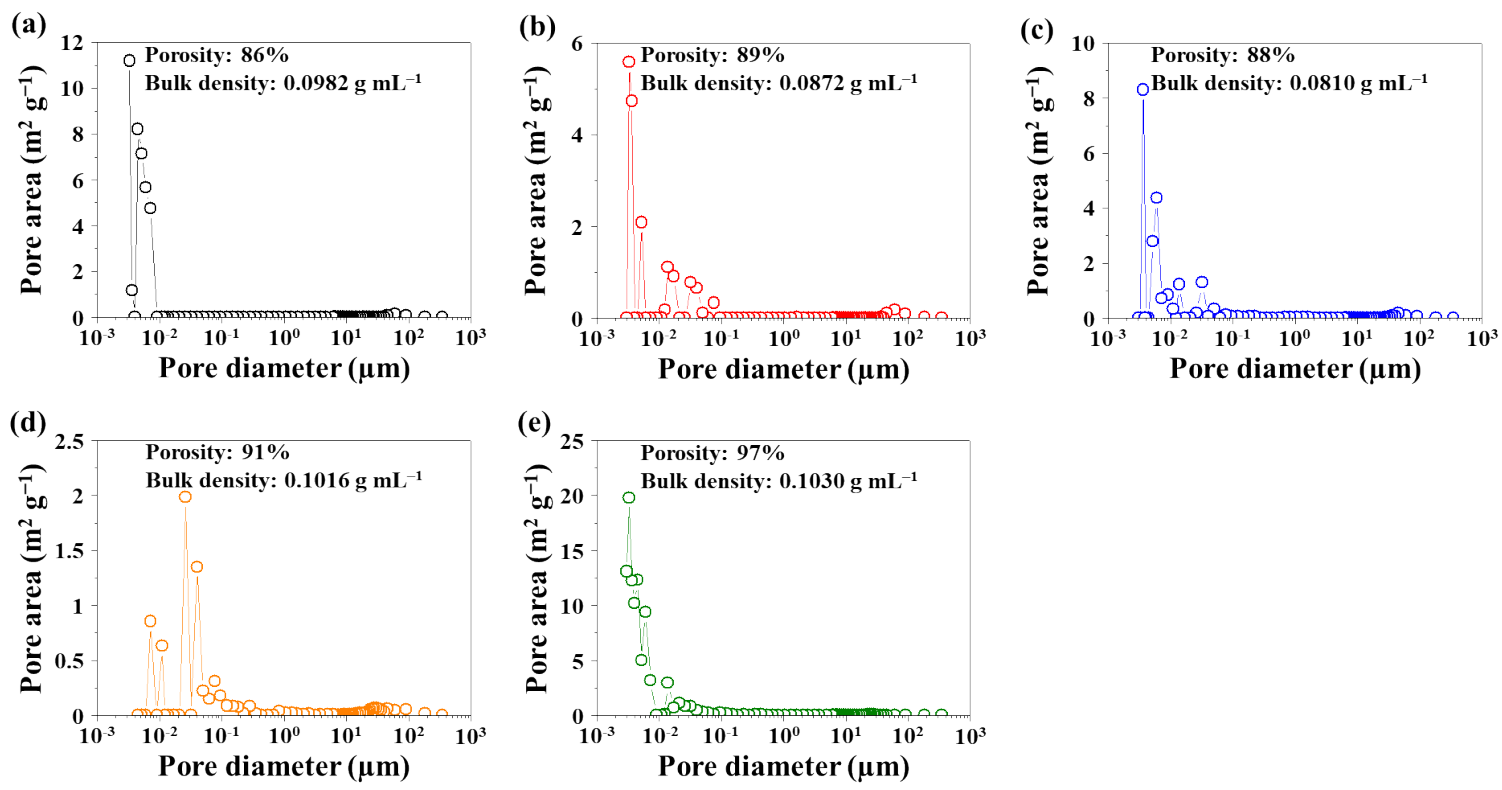

Figure S3. (a-e) Pore size distribution of (a) the pristine fabric, (b) C210, (c) C240, (d) C270, and (e) C300.
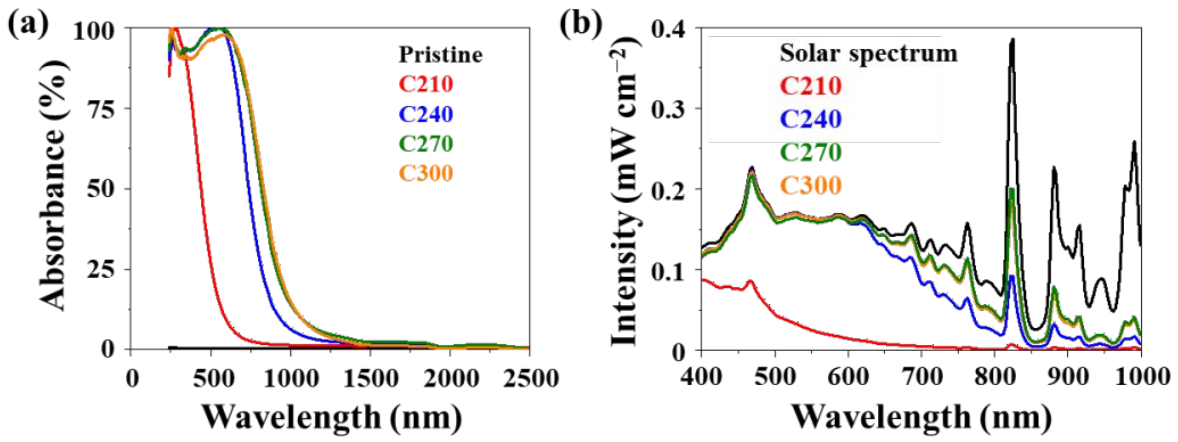

Figure S4. (a) The absorbance of the pristine fabric and the photothermal fabrics over UV-VisNIR range. (b) The solar simulator spectrum and the estimated solar absorption spectra of the photothermal fabrics based on the absorbance of (a). 

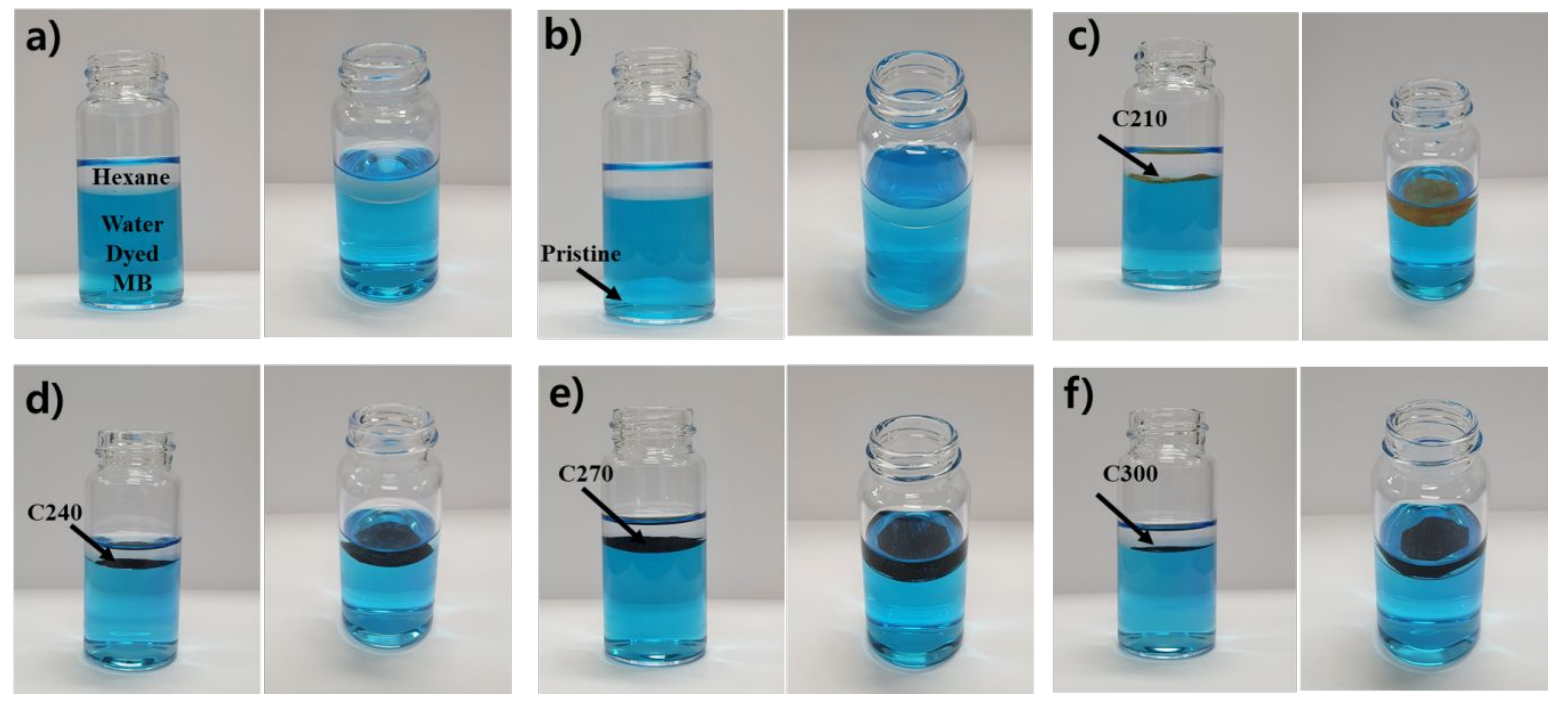

Figure S5. Photographs showing hexane and methylene blue-dyed water taken at two different angles, where (a) none, (b) the pristine fabric, (c) C210, (d) C240, (e) C270, and (f) C300 were added. The pristine fabric sunk at the bottom of water, whereas the carbonized fabrics located at the interface of hexane and water.
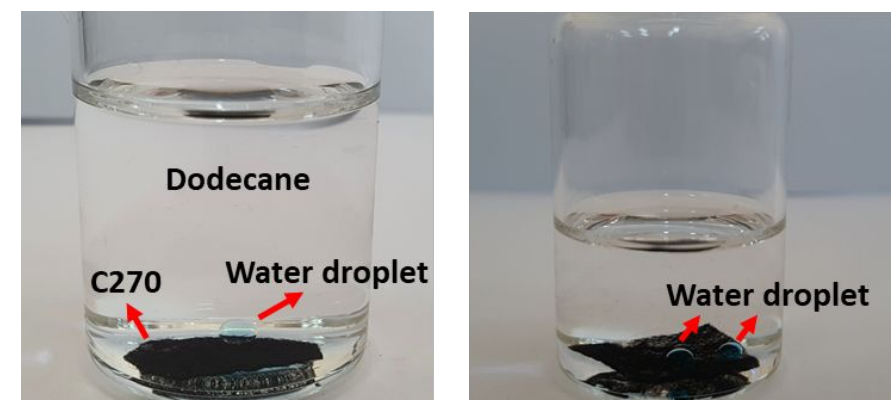

Figure S6. Photographs showing water droplets (dyed with methylene blue) placed on the fabric (C270) immersed in dodecane. 

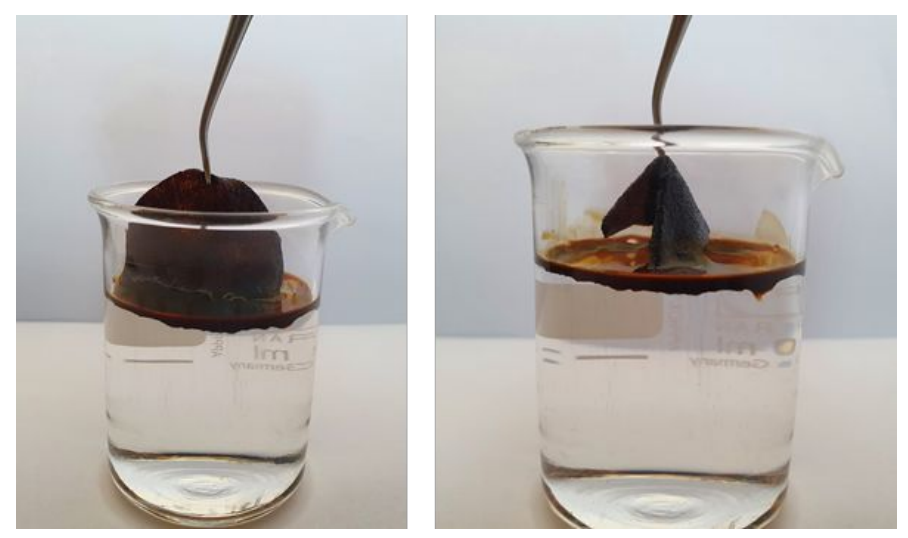

Figure S7. Photographs of collecting crude oil-absorbed carbonized fabrics (C270)

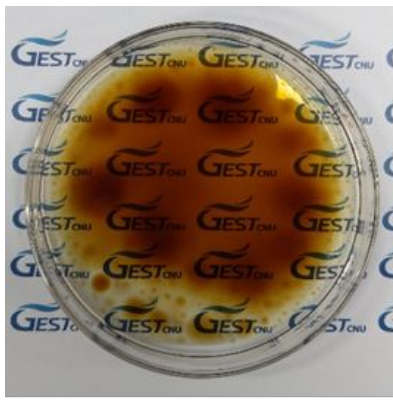

0 min

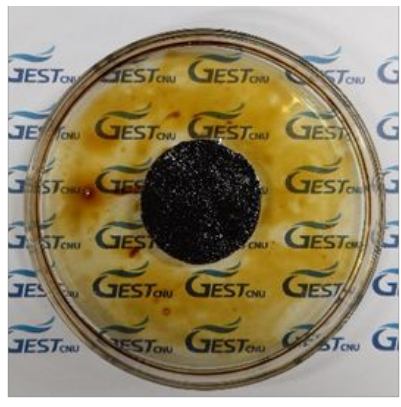

$5 \min$

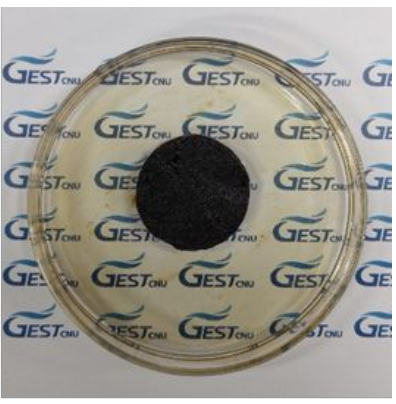

$25 \min$

Figure S8. Photographs showing the fast adsorption of the crude oil spilled on water by photothermal fabric in 5 minutes up to the full adsorption capacity and the additional adsorption under 1 sun irradiation in 25 minutes as light oil components were evaporated by photothermal heating. 

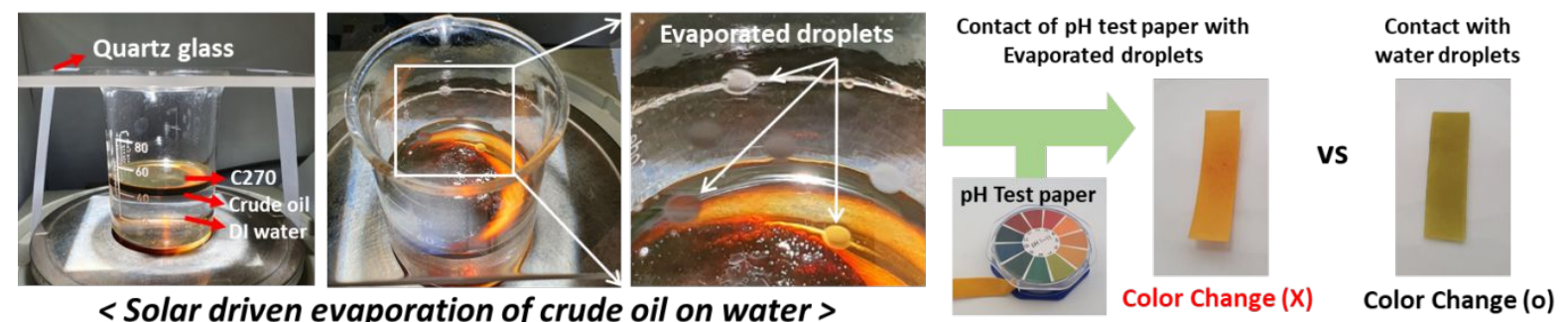

Figure S9. A simple test confirming the absence of water in the evaporated components by using $\mathrm{pH}$ test paper

Reference.

[1] ACS Sustainable Chem. Eng. 2017, 5, 4665-4671. 